\title{
Treatment of chest burn contracture causing respiratory compromise with island release and grafting using cross-link collagen and Integra ${ }^{\mathrm{TM}}$ bilayer dressing
}

\author{
Neil Doctor BS, Erin Woller MD, Sharmila Dissanaike MD
}

\begin{abstract}
Post-burn skin contractures of the anterior and lateral abdomen and chest may result in respiratory compromise due to limitation of rib excursion. This case report describes a young man with respiratory compromise limiting his daily activity and function, as a result of a 90\% burn sustained 6 years previously. Release of his chest and upper abdomen was achieved using "island" scar releases and a cross-linked bovine tendon collagen and glycosaminoglycan and a semi-permeable polysiloxane bilayer matrix dressing (Integra ${ }^{\mathrm{TM}}$ ) followed by subsequent split thickness skin graft. An immediate increase in maximal inspiratory volume was obtained intra-operatively and in the immediate post-operative period, and this improvement was sustained after healing of all wounds with subjective relief of the patient's symptoms.
\end{abstract}

Key words: Integra, Contracture Release, Island Scar Release

\section{INTRODUCTION}

The development of scar contractures, especially of the torso and joints, cause various functional defects for burn victims. ${ }^{1}$ While recent studies have shown various respiratory complications as a result of burns circumferential torso scars are specifically recognized as having a detrimental effect on breathing. ${ }^{2,3}$ Furthermore, Demling et al. found that pulmonary dysfunction often arises from skin grafts on the chest and abdomen, demonstrating the noncompliance of tissue from typical graft procedures and burn wounds. However, little research has been done on

Corresponding author: Sharmila Dissanaike MD Contact Information: sharmila.dissanaike@ttuhsc.edu DOI: 10.12746/swrccc2014.0206.074 scar removal to increase respiratory function. Current literature shows chest wall reconstruction to increase respiration, and one pediatric case established thoracic scar resections as having a positive impact on ventilation. ${ }^{5,6}$ We present a case that demonstrates the physical restriction of breathing from chest contractures and describe a relatively simple, two-stage procedure that is easily replicable and produced good functional and cosmetic results.

\section{Case Presenttion}

A 17 -year-old male patient with $90 \%$ total body surface area burns at age 11 presents with shortness of breath upon minimal exertion which restricted his ability to participate in age-appropriate activities of 
daily living. He also had significant restriction of right arm movement due to contractures. On examination, concentric contracture of the scars across his chest and upper abdomen were noted, with restriction most pronounced anteriorly and laterally, which are the areas of greatest movement during normal respiration.
He had an exaggerated and paradoxical excursion of his lower abdomen during respiration as a compensatory mechanism. His maximal inspiratory volume measured by incentive spirometry was $1700 \mathrm{ml}$. Contracture along the anterior axilla limited his ability to abduct his arm to 90 degrees (Figure 1).

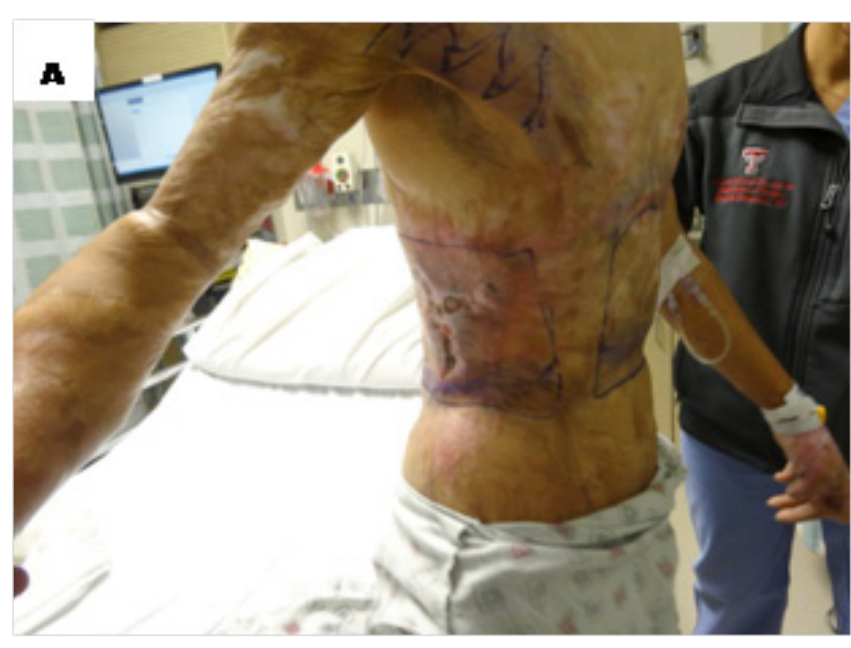

Figure 1A: Right flank markings in preparation of scar release. Y-V-plasty markings can be seen on right axillary contracture

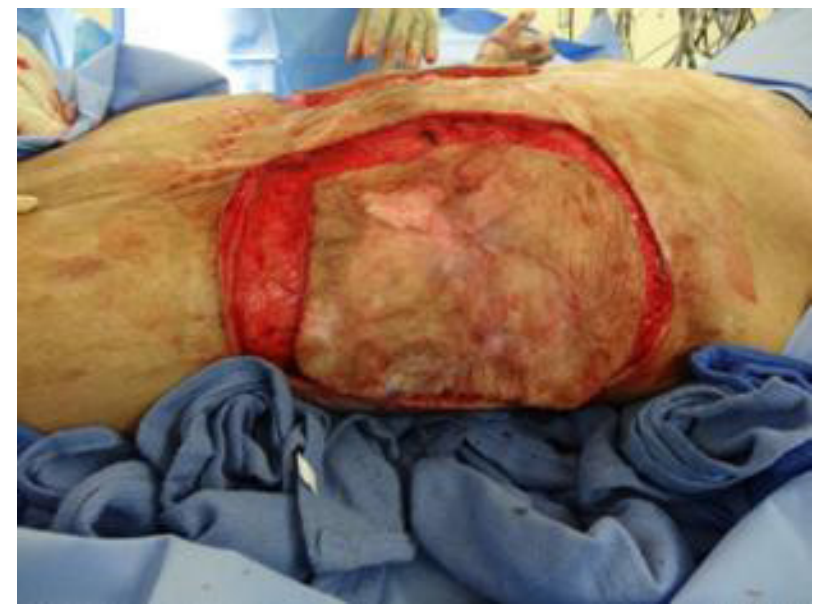

Figure 2: Left flank scar after release

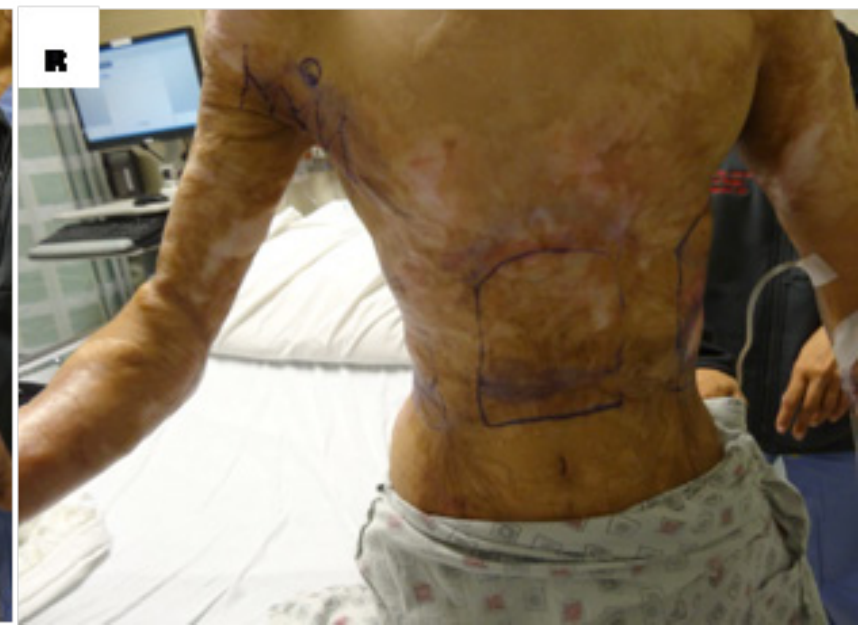

Figure 1B: Anterior scar release markings

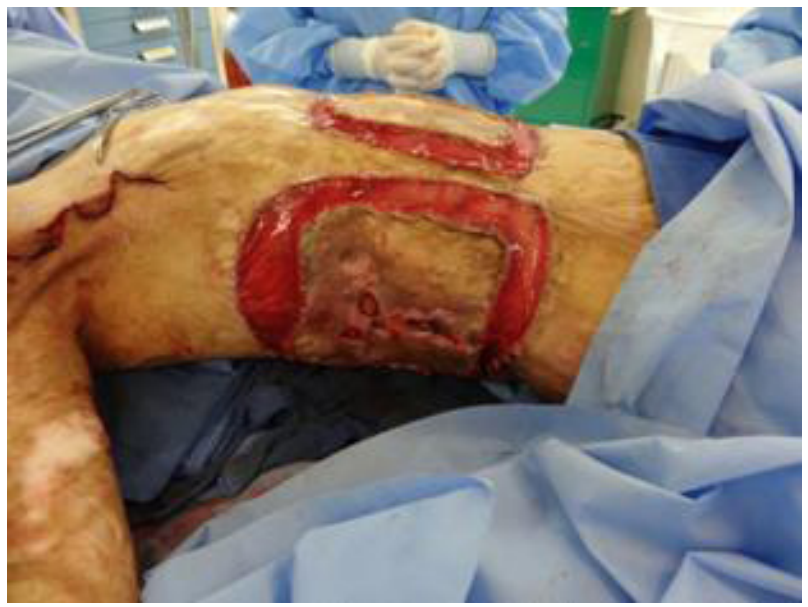

Figure 3: Anterior and right flank wound beds after application of Integra bilayer 
A staged procedure was planned, where the circumferential torso scar was first released by developing three "islands" of scar, with release down to fascia along all edges (Figure 2). This allowed immediate improvement in the expansion of the chest and abdomen, with a $150 \mathrm{ml}$ increase in tidal volume under anesthesia. Following this resection, Integra ${ }^{\mathrm{TM}}$ Meshed Bilayer Wound Matrix (Integra LifeSciences Corp, Plainsboro, NJ) was used to fill the wound bed. The Integra ${ }^{\mathrm{TM}}$ sheets were measured, meshed, and fitted to the wound via staples (Figure 3).

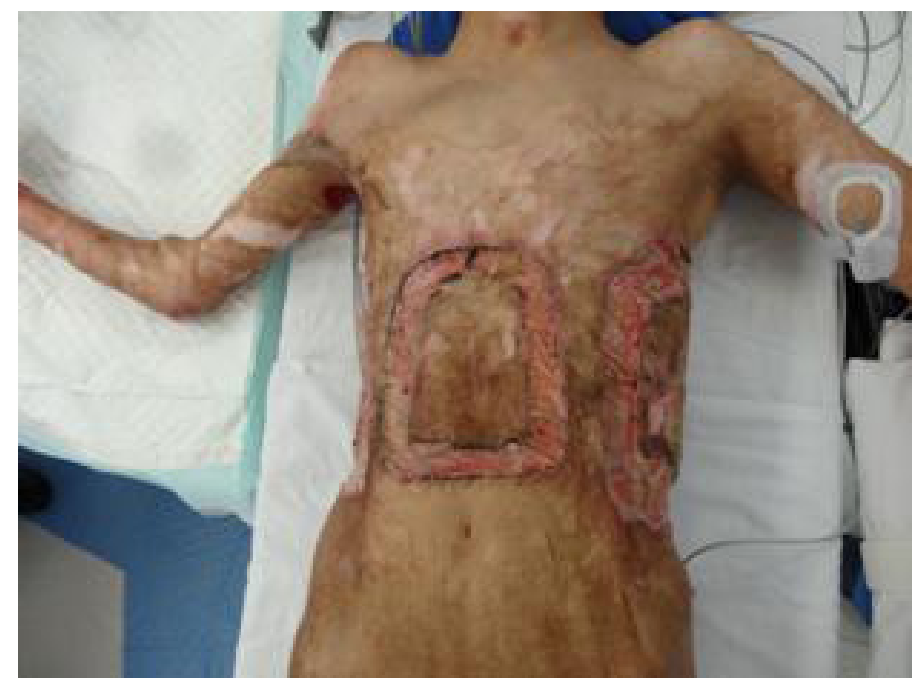

Figure 4: Anterior and left flank wound beds after application of graft

On the first post-operative day the patient's maximum inspiratory volume was $2200 \mathrm{ml}$ on incentive spirometry which improved to $2500 \mathrm{ml}$ at discharge. Three weeks after the first operation, the Integra ${ }^{\mathrm{TM}}$ appeared well vascularized. During the second surgery, the silicone layer of the double mesh was peeled away from the wound bed and a thin sheet graft was then placed on the abdominal regions, atop the remaining layer of Integra ${ }^{\mathrm{TM}}$ (Figure 4). The patient has subsequently recovered well and had relief of his original symptoms.

\section{Discussion}

Burn contractures of the chest, especially in areas of maximal rib excursion, may present a large hindrance to respiration. Contractures can lead to multiple problems, including decreased range of motion of joints, increased difficulty breathing, and further complications of wound care and treatment. ${ }^{7}$ Studies have shown severe functional limitations and disfigurement from scars and have demonstrated the need to promptly and adequately treat burn wounds to prevent contractures from forming. ${ }^{8-9}$ Chest contractures have also arisen iatrogenically from breast augmentation and reconstruction. ${ }^{10-11}$ Regardless of the etiology, chest contractures (and contractures in general) cause multiple complications, and their treatment and prevention is important.

The current literature reports numerous techniques and procedures to address burn wounds and contractures. Following the resection of scar tissue, skin flaps are heavily used in surgery. The merits of local flaps, ${ }^{12-13}$ split-thickness dermal grafts, ${ }^{14}$ and "super-thin" flaps ${ }^{15}$ have been discussed extensively for the treatment of burn wounds, but each technique has certain drawbacks. Local turn-over flaps allow for exceptional coverage over larger wound areas and cause less contracture than traditional methods, but healthy tissue in severe burns is often not available. Split-thickness grafts and super-thin flaps offer the advantage of harvesting less tissue for full thickness burns, allowing for quick healing of the donor site, and re-harvesting within 6 to 8 weeks. However, both conventional split-thickness grafts and super-thin flaps are associated with significant contracture development resulting from a relative lack of dermis. ${ }^{17}$ Finally, cultured epithelial autografts and allografts have been used broadly in reconstruction and burn wounds as a method of gaining larger graft sizes but take a great deal of time to grow, are costly, and have relatively lower engraftment rates.

In the first stage of the case presented, resection of the large contractures and scar area was 
done using an island scar release technique. Linear scar contractures are usually treated with $\mathrm{V}-\mathrm{Y}$ plasty or various types of local flaps, ${ }^{23-25}$ but these procedures are not effective for wide or multiple contractures. ${ }^{26}$ Furthermore, patients with large amounts of burn scars lack suitable donor sites for autografts. In these instances, a circumferential incision technique is effective at releasing the multiple contracture lines, such as those located on the torso, and minimizes the amount of grafted tissue needed for the wound bed. ${ }^{27}$ Using this particular technique in the three locations on the patient's chest offered a long term solution for the removal of tension lines across the torso and a rapid increase and maintenance of inspiratory volume.

After resecting the contracted tissue via island scar release, the second stage included covering of the wound beds with Integra ${ }^{\mathrm{TM}}$ Bilayer Matrix Wound Dressing (a porous matrix of cross-linked bovine tendon collagen and glycosaminoglycan and a semipermeable polysiloxane (silicone layer)). Harrison et al. have made the case that in vitro engineered tissue should be explored for wound healing and graft placement after burns. Using synthetic films, such as Integra ${ }^{\mathrm{TM}}$, has the benefit over traditional procedures of autologous flaps and grafts in which scar contractures sometimes gradually reappear. ${ }^{28}$ The use of Integra ${ }^{\mathrm{TM}}$ has been well documented in cases of challenging locations and in burn wounds with excessive scarring and contractures. ${ }^{29-30}$ As mentioned previously, the standard practice of expanded, meshed split-thickness skin autografts achieve wound closure over larger areas, but its disadvantages include fragile wound beds, suboptimal appearance, reduced pliability, and scarring. In patients with large burns, the necessity of multiple flaps and grafts requires repeated harvesting from a donor site; subsequent harvesting makes thinner and lesser quality local flaps. ${ }^{18,30}$ Synthetic dressings such as Integra ${ }^{\mathrm{TM}}$ are readily available; this overcomes the burden of finding suitable donor sites, and, perhaps of more importance, the application of Integra ${ }^{\mathrm{TM}}$ to cleaned wound beds allows for fewer contractures to develop during the postoperative period than traditional flaps. ${ }^{31}$ The primary drawback of Integra ${ }^{\mathrm{TM}}$, especially in developing countries, is the cost of each unit. The average cost of an 8"x10" sheet is \$2000; however, Ryan et al. have shown a correlation between treatment with Integra ${ }^{\mathrm{TM}}$ and a decrease in duration of hospital stay, possibly making the usage of Integra ${ }^{\mathrm{TM}}$ a cost effective solution.

\section{Conclusions}

In summary, the use of Integra ${ }^{\mathrm{TM}}$ for burn scar contracture is a valid option in scar release and a novel method to increase the respiratory volume in burn patients. The patient had an increase in the abduction degree of his right arm and a marked increase in his respiratory function, helping alleviate his shortness of breath. Integra ${ }^{\mathrm{TM}}$ Bilayer Matrix Wound Dressing allows for a good functional result from the resection of scar tissue and contractures.

Author Affiliation: Neil Doctor is a medical student at TTUHSC in Lubbock, TX. Erin Woller is a surgery resident at TTUHSC in Lubbock, TX. Sharmila Dissanaike is trauma and burn surgeon at TTUHSC in Lubbock, TX.

Received: 01/09/2014

Accepted: 03/30/2014

Reviewers: Isham Huizar MD

Published electronically: 04/15/2014

Conflict of Interest Disclosures: None

\section{REFERENCES}

1. Richard RL, Lester ME, Miller SF, Bailey JK, Hedman TL, Dewey WS, et al. Identification of cutaneous functional units related to burn scar contracture development. J Burn Care Res $2009 ; 30: 625-31$. 
2. Boots RJ, Dulhunty JM, Paratz J, Lipman J. Respiratory Complications in Burns: An Evolving Spectrum of Injury. Clinical Pulmonary Medicine 2009; 16:132-8.

3. Hettiaratchy S, Papini R. Initial management of a major burn: I--overview. BMJ 2004; 328:1555-7.

4. Demling RH, Crawford G, Lind L, Read T. Restrictive pulmonary dysfunction caused by the grafted chest and abdominal burn. Crit. Care Med 1988; 16:743-7.

5. Netscher DT, Baumholtz MA. Chest reconstruction: I. Anterior and anterolateral chest wall and wounds affecting respiratory function. Plast Reconstr Surg 2009; 124:240e-52e.

6. Quinby WC Jr. Restrictive effects of thoracic burns in children. J Trauma 1972; 12:646-55.

7. Schneider JC, Holavanahalli R, Helm P, Goldstein R, Kowalske K. Contractures in burn injury: defining the problem. J Burn Care Res 2006; 27:508-14.

8. Goel A, Shrivastava P. Post-burn scars and scar contractures. Indian J Plast Surg 2010; 43:S63-71.

9. Liu JH, Fang CH. Treatment for severe burns of the chest wall with special reference to the involved ribs. Burns Incl Therm Inj 1987; 13:398-400.

10. Adams WP Jr. Capsular contracture: what is it? What causes it? How can it be prevented and managed? Clin Plast Surg 2009; 36:119-126, vii.

11. Benediktsson K, Perbeck L. Capsular contracture around saline-filled and textured subcutaneously-placed implants in irradiated and non-irradiated breast cancer patients: five years of monitoring of a prospective trial. $J$ Plast Reconstr Aesthet Surg 2006; 59:27-34.

12. Chu EA, Byrne PJ. Local flaps I: bilobed, rhombic, and cervicofacial. Facial Plast Surg Clin North Am 2009; 17:349-60.

13. Dolan RW. Facial Plastic, Reconstructive, and Trauma Surgery. New York: Marcel Dekker; 2004.

14. Rubis BA, Danikas D, Neumeister M, Williams WG, Suchy $\mathrm{H}$, Milner SM. The use of split-thickness dermal grafts to resurface full thickness skin defects. Burns 2002; 28:752-9.

15. Oki K, Hyakusoku H, Murakami M, Oki K. Dorsal intercostal perforator (DICP) augmented scapular "super-thin flaps" for the reconstruction of extensive scar contractures in the axilla and anterior chest: a case report. Burns 2005; 31:105-7.

16. Yang JY, Tsai YC, Noordhoff MS. The application of turnover flaps to burn wounds. Burns Incl Therm Inj 1985; 12:11521.

17. Loss M, Wedler V, Künzi W, Meuli-Simmen C, Meyer VE. Artificial skin, split-thickness autograft and cultured autologous keratinocytes combined to treat a severe burn injury of $93 \%$ of TBSA. Burns 2000; 26:644-52.

18. Hansbrough JF. Current status of skin replacements for coverage of extensive burn wounds. J Trauma 1990; 30:S155-160.

19. Bell E, Ehrlich HP, Buttle DJ, Nakatsuji T. Living tissue formed in vitro and accepted as skin-equivalent tissue of full thickness. Science 1981; 211:1052-4.

20. Desai MH, Mlakar JM, McCauley RL, Abdullah KM, Rutan RL, Waymack JP, et al. Lack of long-term durability of cultured keratinocyte burn-wound coverage: a case report. J Burn Care Rehabil 1991; 12:540-5.

21. Clugston PA, Snelling CF, Macdonald IB, Maledy HL, Boyle JC, Germann E, et al. Cultured epithelial autografts: three years of clinical experience with eighteen patients. J Burn Care Rehabil 1991; 12:533-9.

22. Woodley DT, Peterson HD, Herzog SR, Stricklin GP, Burgeson RE, Briggaman RA, et al. Burn wounds resurfaced by cultured epidermal autografts show abnormal reconstitution of anchoring fibrils. JAMA 1988; 259:2566-71.

23. Cooper MA. The multiple Y-V plasty in linear burn scar contracture release. Br J Plast Surg 1990; 43:145-9.

24. Ogawa R, Hyakusoku H, Murakami M, Koike S. Reconstruction of axillary scar contractures--retrospective study of 124 cases over 25 years. Br J Plast Surg 2003; 56:100-5.

25. Lin T-M, Lee S-S, Lai C-S, Lin S-D. Treatment of axillary burn scar contracture using opposite running Y-V-plasty. Burns 2005; 31:894-900.

26. Suzuki S, Isshiki N, Ishikawa K, Ogawa Y. The use of subcutaneous pedicle flaps in the treatment of postburn scar contractures. Plast Reconstr Surg 1987; 80:792-8.

27. Ezoe K, Yotsuyanagi T, Saito T, Ikeda K, Yamauchi M, Arai $\mathrm{K}$, et al. A circumferential incision technique to release wide scar contracture. J Plast Reconstr Aesthet Surg 2008; 61:1059-64.

28. Harrison CA, MacNeil S. The mechanism of skin graft contraction: an update on current research and potential future therapies. Burns 2008; 34:153-63.

29. Dantzer E, Braye FM. Reconstructive surgery using an artificial dermis (Integra): results with 39 grafts. Br J Plast Surg 2001; 54:659-64.

30. Pham TN, Gibran NS. Thermal and electrical injuries. Surg Clin North Am 2007; 87:185-206, vii-viii.

31. Stiefel D, Schiestl C, Meuli M. Integra Artificial Skin for burn scar revision in adolescents and children. Burns 2010; 36:114-20.

32. Ryan CM, Schoenfeld DA, Malloy M, Schulz JT 3rd, Sheridan RL, Tompkins RG. Use of Integra artificial skin is associated with decreased length of stay for severely injured adult burn survivors. J Burn Care Rehabil 2002; 23:311-7. 